\title{
EVALUATION OF NUMBER OF RENAL ARTERIES IN LIVE RELATED RENAL DONORS BY CT ANGIOGRAPHY AND CONVENTIONAL ANGIOGRAPHY
}

\author{
Amjad Sattar ${ }^{1}$, Shabbir Naeem ${ }^{2}$, Ahsan Ali, Mustafa Akhtar ${ }^{2}$, Adeeb Rizvi ${ }^{2}$ \& Anwar Naqvi ${ }^{2}$ \\ 1. Dow University Hospital, Radiology. \\ 2. Sindh Institute of Urology \& Transplant \\ Corresponding author email: amj7777@ @otmail.com
}

\begin{abstract}
Renal transplantation represents the best available replacement treatment for patients with end stage renal disease patients than performing dialysis, and living donor transplantation has been shown to offer better graft survival than cadaver donor renal transplantation. It was demonstrated that kidneys from living, unrelated donors succeed as well as kidneys obtained from brothers and sisters who share half of the tissue matching antigens with kidney recipients. The study was carried out at department of Angiography, Sindh Institute of Urology and Transplantation (SIUT) from January 2009 to September 2011. A total of 30 patients were included in the study. Informed consent was taken from all patients. Result demonstrates a total of 115 renal arteries in 60 kidneys of donors were depicted at CT angiography (CTA). Only 57 of kidneys showed more than one or multiple arteries, 52 of these had two renal arteries, and 6 had three renal arteries.
\end{abstract}

\section{KEYWORDS}

Transplantation, Conventional angiography, Angiography, Renal arteries

\section{INTRODUCTION}

Renal transplantation has grown rapidly over the past 30 years, resulting in an inadequate supply of organs to meet the everincreasing demand. This has led to an increase in the number of living-related donors (Rankin, 2001). Renal transplantation leads to better survival and quality including detailed medical history, laboratory testing and of life for patients with renal failure. It has become the treatment of choice for the end stage renal disease (Kaynan, 1999). Renal transplantation represents the best available replacement treatment for patients with end stage renal disease patients than performing dialysis, and living Donor renal transplantation has been shown to offer better graft survival than cadaver donor renal transplantation. However, adequate preoperative living kidney donor evaluation is mandatory to reduce the possible occurrence of surgical complications that can threaten the graft, and sometimes the survival of the recipient (Letourneau, 1998). It was demonstrated that kidneys from living, unrelated donors succeed as well as kidneys obtained from brothers and sisters who share half of the tissue matching antigens (HLA antigens) with the kidney recipient. Thus, the pool of potential renal donors has expanded from first-degree relatives to include distant relatives, spouses, and close friends. The success rate of living donor kidney transplants, whatever the donor-recipient relationship, is significantly greater than that for cadaver kidneys. The estimated half-life (the period after which 50\% of transplanted kidneys are still functional) of cadaver kidneys is 8.6 years, whereas the half-life of living donor kidneys is 14.7 years. Overall patient survival is also superior with living donor transplantation. It is also of utmost significance to minimize the risk to the potential living kidney donor. In addition, accurate delineation of renal anatomy to assist in surgical planning is a prerequisite for a successful transplant operation. Preoperative radiological evaluation of kidney donors is used to select the patient and the kidney that is to be harvested. Traditionally, renal angiography and excretory urography have been used to evaluate potential kidney donors (Pozniak, 1998; Cochran, 1996). However, several studies have shown that helical computed tomography (CT) angiography can replace excretory urography and renal angiography in the evaluation of potential kidneys donors and helical CT angiography and conventional angiography has become an accepted method for the preoperative evaluation of living donors according to some authors (Alfrey, 1995; Cocheteun, 2001). We therefore wanted to evaluate and compare the two modalities in our setting in terms of number of renal arteries identified pre operatively using both modalities.

\section{MATERIALS AND METHOD}

This study was carried out in the Department of Angiography, Sindh Institute of Urology and Transplantation (SIUT) from January 2009 to September 2011. All patients were referred to the radiology department for preoperative Conventional Angiography examination. A total of 30 patients were included in the study. Informed consent was taken from all the patients. A complete history was taken from all patients especially for that of any previous contrast reaction. The base line investigations were reviewed. All patients underwent evaluation by CT Angiography. The CT finding was reviewed and those, with multiple renal arteries on the scans then were prepared for conventional angiography. Conventional renal angiography examinations were performed in angiography suit by a trained Radiologist. The procedures were performed on Digital Subtraction angiography machine (Toshiba KXO100 G) which uses an X-ray generator maximum potential of $150 \mathrm{kVp}$ and a maximum current $1,300 \mathrm{~mA}$, together with a water-cooled $\mathrm{x}$-ray tube having a heat capacity of 1 .8 million BTUs and nominal focal spots of $0.6,1$, and $2 \mathrm{~mm}$, All procedures were performed on Digital Subtraction angiography machine (Toshiba KXO100 G) at frame rate $3 \mathrm{fr} / \mathrm{s}$. The usual dose of contrast material (omnipac) was $2 \mathrm{~mL} / \mathrm{kg}$ and the average single injection ranged from 30 to $40 \mathrm{ml}$. Routine protocol for conventional angiography examination was followed. Instructions for 6 to 8 hours fasting were given to the patient when appointment was given. Patient's relevant medical history was re-obtained 
regarding hypertension, diabetes mellitus, asthma and allergies. If patient suffered from any of the mentioned condition, the appropriate preparation including laboratory evaluation e.g. Complete blood count, Prothombin time, International normalize ratio, creatinine, urea, platelets, electrolytes, hepatitis B,C were carried out. If the patient had infectious diseases e.g. HEPATITIS, MARO, MARSA, VRE the angiographer was informed. On the day of conventional angiography examination, Informed consent was re-obtained from all patients. Informed consent included a discussion; risk of hematoma, thrombosis, dissection of vascular cases, contrast agents; including allergic reactions and nephrotoxicity, catheter manipulation e.g. risk of bleeding, embolization, perforation, arrhythmias, and stroke. Patient had both groins shaved and was dressed up in loosely fitted hospital gown and all the metallic ornaments and jewellery were removed. An 18-gauge venous line was placed, usually in an antecubital fossa vein. The procedure was completely explained and breathing instructions were also given. The need to remain absolutely still was emphasized. The place where the catheter to be inserted was cleaned and sterilized with the help of aseptic technique. Under fluoroscopy, the site of femoral head was detected with the help of blade scalapel in order to puncture the femoral artery. Then 16 guage angio needle was inserted into the blood vessel. A short guide wire was inserted through the needle into the blood vessel, the needle and short guide wire was removed. Then the pig tail(5fr) catheter was placed over the guide wire $(0.35$ inch $)$ and moved at the level of L2 vertebrae where renal artery divide and then the guide wire was removed, the contrast was injected to see the angiogram of renal vasculature. The usual dose of contrast material (omnipac) was $0.5-1.0 \mathrm{ml} / \mathrm{kg}$ and the average single injection ranged from 30 to $50 \mathrm{ml}$ at 10 or $12 \mathrm{mI} /$ second from the injector. Patient was asked to take a breath and hold it for several seconds. Several radiographic pictures were taken one after another. Then removed pig tail catheter by using guide wire. After that confirmation of renal arteries (accessory, prehilar and lobar) on both kidney by using RDC (5fr) catheter super selectively was done in order to see the renal arteries. Catheters were withdrawn after the interventional procedure. Sufficient compression was applied directly at above the puncture site to stop the bleeding but maintain blood flow. Pressure was applied for 10 to 20 minute or until bleeding has stopped. . A bandage was applied on the site. A sandbag was placed on the site to hold pressure. Patients were asked to keep the right leg straight for 6 to 8 hours. Vital were checked every 30minute in 2 hours and hourly for 4 hours. Dorsalispedis pulse of left leg was checked frequently.

\section{RESULTS}

A total of 115 renal arteries in 60 kidneys of donors were depicted at CT angiography (CTA). Only 57 of kidney were shown to have more than one or multiple arteries, 52 of these had two renal arteries, and 6 had three renal arteries (total number of accessory arteries at CT, 13). At conventional angiography (CA), 112 arteries were identified in 60 kidneys of donors. 12 of the 60 kidneys had three arteries, 64 had more than one or multiple arteries, and 36 had two arteries. The overall accuracy of CT for the detection of renal arteries was $94 \%$ (107 of 115 arteries in 88 of 94 kidneys. (Fig 01).

(Total number of accessory arteries at CA, 20). Nine accessory arteries were interpreted in nine kidneys; three were initially missed and six were over estimated at CT (Table 01).

\begin{tabular}{|c|c|c|c|c|}
\hline \multirow{2}{*}{$\begin{array}{l}\text { DONORS RENAL } \\
\text { ARTERIES }\end{array}$} & \multicolumn{2}{|c|}{ COMPUTED TOMOGRAPHY } & \multicolumn{2}{|c|}{ CONVENTIONAL ANGIOGRAPHY } \\
\hline & NO OF KIDNEYS & $\begin{array}{l}\text { FINDINGS } \\
\%\end{array}$ & NO OF KIDNEYS & $\begin{array}{l}\text { FINDINGS } \\
\%\end{array}$ \\
\hline DOUBLE & 52 & $45 \%$ & 36 & $32 \%$ \\
\hline TRIPLE & 6 & $5 \%$ & 12 & $10 \%$ \\
\hline MULTIPLE & 57 & $\mathbf{5 0 \%}$ & 64 & $59 \%$ \\
\hline
\end{tabular}

Table 1: Performance of CTA and CA in the evaluation of donor renal arteries 


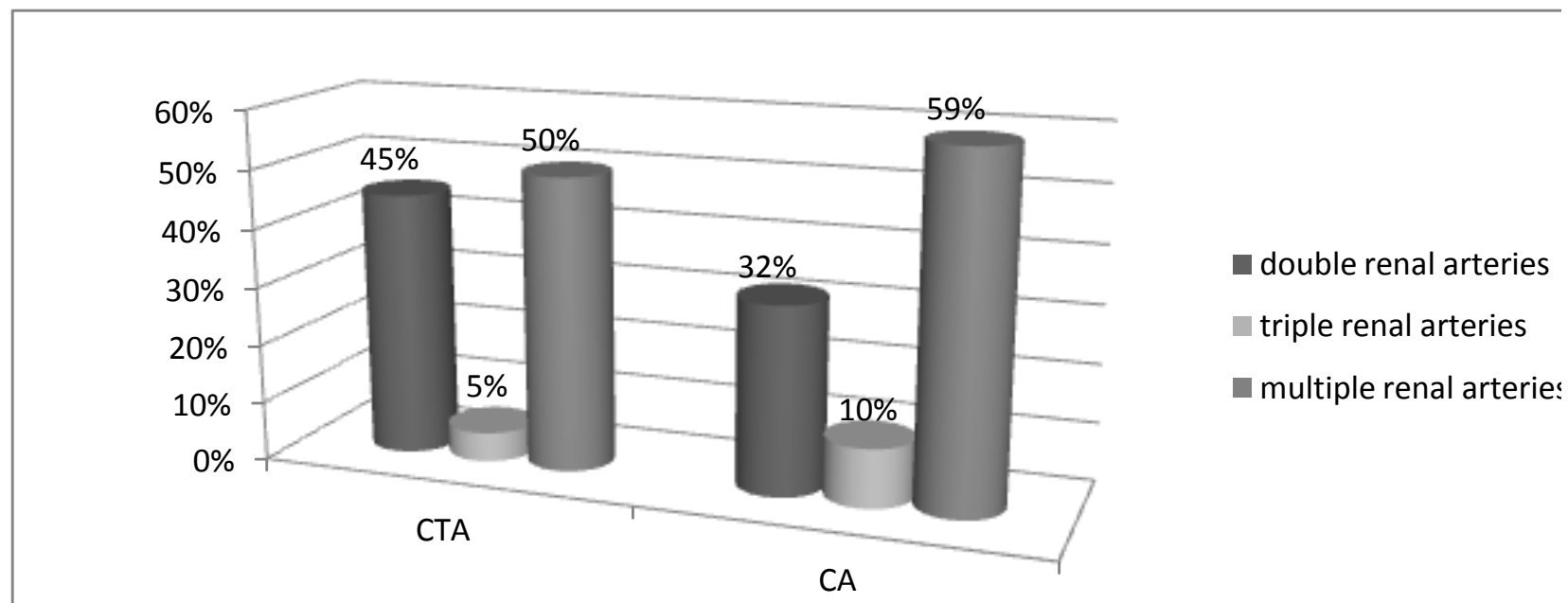

Figure 1: Comparison between CTA and CA findings in percentages

All three accessory arteries that were missed at the initial interpretation were confidently identified at retrospective review of the transverse CT scans. On the post processed three-dimensional images, only one of the three missed accessory arteries could be seen. Two missed accessory arteries appeared as early branching
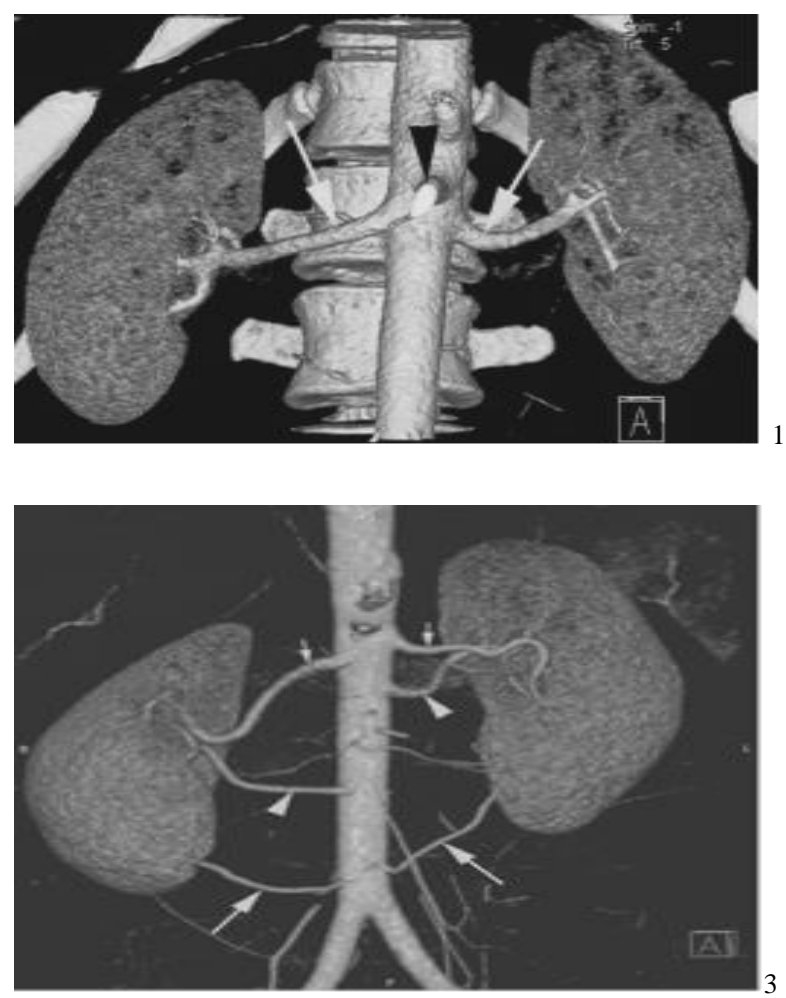

on the three-dimensional images because of their close origin and course with the main renal artery from the aorta. At CA, all of these three accessory arteries were identified. No complication from either CTA or CA was noted.
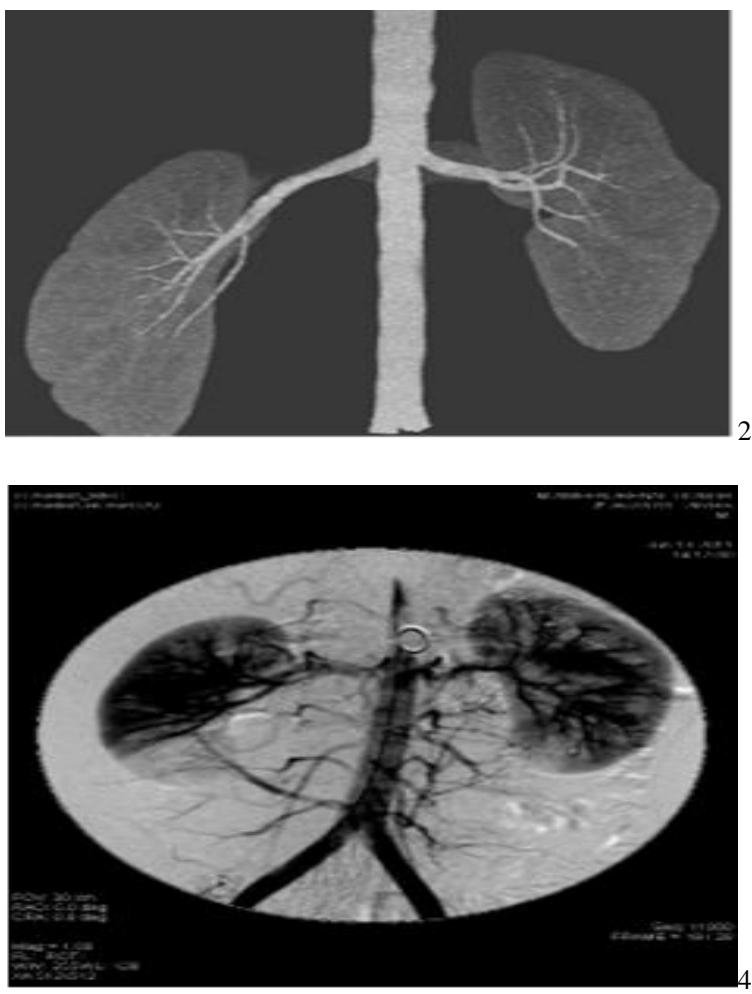


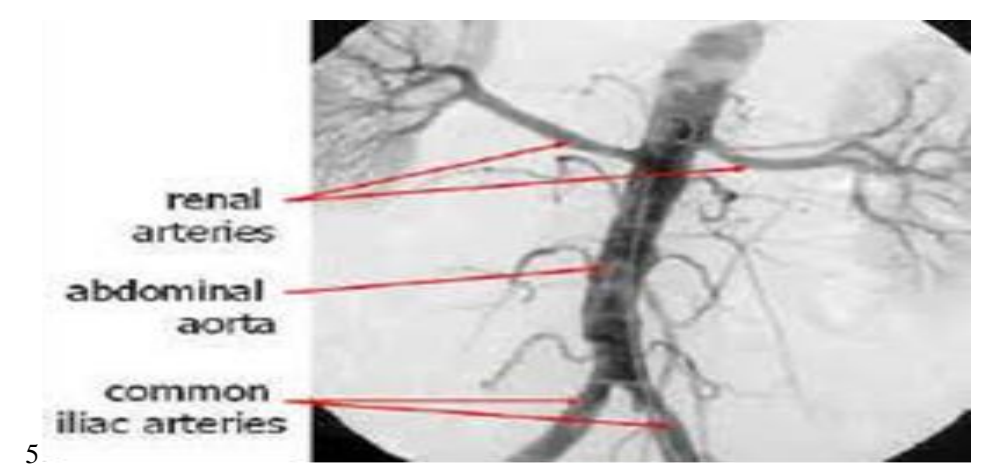

1, 2, 3 are CT Angiography images, 4and 5 Conventional angiography image

\section{DISCUSSION}

The only curative therapy for patients with end-stage renal disease is renal transplantation. In the past decade, there has been a substantial increase in living kidney transplantations (Low, 1998; Spring, 1979). Renal transplantation from a living donor raises additional problems for the surgeon. The donor surgery must go smoothly, all potential problems must be identified preoperatively, and the investigations must be risk-free and kept to a minimum (Cochran, 1996). The most crucial data to be gathered before renal transplantation are data about the vascular anatomy of the donor kidney. The anatomic information required before conventional open and minimally invasive surgery in living kidney donors includes the number, length, location, and branching pattern of the renal arteries and the status of the donor kidney and its venous and collecting systems (Beregi, 1999). The role of renal angiography in the preoperative examination of living related donors is well established. The objectives are to identify the number and origin of the renal arteries and the presence of early branching arteries and to exclude unsuspected Reno vascular or parenchymal abnormalities that will influence the choice of kidney. Unsuspected multiple renal arteries may be found at surgery and can usually be anastomosed; they are not a contraindication to donation Early branching arteries may be more of a problem technically. Renal angiography has some potential risks, although the complications are markedly reduced with the use of small catheters in association with digital subtraction angiography (Rubin, 1994). CT angiography, which is non-invasive, has been used for the assessment of renal artery stenosis and living kidney donors (Beregi, 1996; Galanski, 1993 \& Kaatee, 1993) with good results, but the ideal would be to replace CT angiography with MR angiography, because MR angiography uses no radiation and the contrast material is less toxic (Chai, 2008). Our data provide information regarding the frequency of different anatomical variants of the renal vasculatures. In a study conducted in Korea using CT angiography to evaluate renal anatomy, the prevalence of multiple arteries and accessory renal arteries were $31 \%$ and $12 \%$, respectively (Smith, 1998). When we compared our data with conventional angiography, we seemed to have had fewer cases of accessory arteries (20\%). Previous studies suggested that laparoscopic donor nephrectomy with multiple arteries was associated with longer operation times and increased blood loss, although neither multiple arteries nor vascular reconstructions influenced recipient creatinine clearance (Rubin, 1995). However, accessory arteries to the lower pole Correlated with an increased rate of ureteral complications (Pozniak, 1998), and therefore it is important to correctly identify these accessory arteries. Apart fr5m accessory arteries, identification of early branching renal arteries. (Cochran, 1996) is also critical. Early branchings of less than $2 \mathrm{~cm}$ in length are technically problematic and have been reported in $10 \%-13 \%$ of potential kidney donors (Mandal, 2001). Researchers concluded that identification of vascular anomalies was best on direct viewing of the axial images using interactive scrolling through the images and cine-loop paging. They compared the accuracy of CT angiography with intraoperative findings in the evaluation of 102 live kidney donors. CT angiography missed an accessory artery that was visualized in retrospect, and a very early branch that was read as accessory artery (Laugharne, 2007). Cochran et al in their prospective study intended to determine if helical CT arteriography plus conventional radiography is sufficiently accurate to replace and less costly than excretory urography and conventional renal arteriography. Of 40 patients who underwent CT arteriography, agreement between results of CT arteriography and conventional arteriography correlated in $89 \%$ of kidneys. Researchers evaluated 19 donors solely by Conventional angiography preoperatively. Five donors $(26 \%)$ had supernumerary renal arteries. Fourteen donors had single, 4 donors had 2 and 1 donor had 3 renal arteries. CA demonstrated small polar vessels in several donors. Accuracy of vascular anatomy defined on CT was $90 \%$ when confirmed at operation which missed a $0.8 \mathrm{~cm}$ lesion near the renal hilum. Patient acceptance was excellent. Of the 30 pairs of living kidney of donors, there were total of 9 discrepancies between the imaging results findings. Arterial anomalies each contributed 3 cases, and all of the missed cases occurred in subjects in whom conventional renal arteriography was used for the preoperative assessment. Both procedures yielded excellent results in terms of delineation of renal vasculature. Contrast nephropathy is a tangible risk in any contrast examination. In our series, there was no documented contrast nephropathy related to either procedure. Previous study showed no significant difference in renal function after CT angiography versus intra-arterial digital subtraction angiography in renal artery stenosis patients. Furthermore, the potential risks of wound hematoma or even to arteriovenous fistula formation as may occur with conventional arteriograms, are virtually nonexistent in CT angiography which only involves intravenous injection of contrast 
medium. In summary, Conventional angiography (CA) is the considered gold standards and it is used to see the renal vasculatures. $\mathrm{CA}$ is a complicated and risky procedure because of its high radiation and patient's dose. It is a decision making procedure in which surgeon and radiologist decides that whatever kidney nephrectomy will be done or not by using CA. CA shows

\section{REFERENCES}

- $\quad$ Alfrey, E. J., Rubin, G. D., Kuo, P. C., Waskerwitz, J. A., Scandling, J. D., Mell, M. W., ... \& Dafoe, D. C. (1995). The Use of Spiral Computed Tomography in the Evaluation of Living Donors for Kidney Transplantation1. Transplantation, 59(4), 643-645.

- Beregi, J. P., Elkohen, M., Deklunder, G., Artaud, D., Coullet, J. M., \& Wattinne, L. (1996). Helical CT angiography compared with arteriography in the detection of renal artery stenosis. AJR. American journal of roentgenology, 167(2), 495-501.

- $\quad$ Beregi, J. P., Louvegny, S., Gautier, C., Mounier-Vehier, C., Moretti, A., Desmoucelle, F., \& McFadden, E. (1999). Fibromuscular dysplasia of the renal arteries: comparison of helical CT angiography and arteriography. AJR. American journal of roentgenology, 172(1), 27-34.

- $\quad$ Chai, J. W., Lee, W., Yin, Y. H., Jae, H. J., Chung, J. W., Kim, H. H., \& Park, J. H. (2008). CT angiography for living kidney donors: accuracy, cause of misinterpretation and prevalence of variation. Korean Journal of Radiology, 9(4), 333-339.

- Cocheteun, B., Mounier-vehier, C., Benagi, J. P. (2001). Variation of renal artery and blood supply. Radiology 2001, 11, 776-779.

- $\quad$ Cochran, S. T, Krasny R.M, Danovitch G.M.( 1996). Helical ct angiography examination of living renal donors. AJR; 167:581-583.

- Cochran ST, Krasny RM, Danovitch GM, Rajfer J, Barbaric ZM, Wilkinson A, et al. (1997). Helical CT angiography for examination of living renal donors. AJR, 168: 1569 -1573

- Galanski, M., Prokop, M., Chavan, A., Schaefer, C. M., Jandeleit, K., \& Nischelsky, J. E. (1993). Renal arterial stenoses: Spiral CT angiography. Radiology, 189(1), 185192.

- $\quad$ Kaatee, R., Beek, F. J., De Lange, E. E., Van Leeuwen, M. S., Smits, H. F., Van der Ven, P. J., ... \& Mali, W. P. (1997). Renal artery stenosis: detection and quantification with spiral CT angiography versus optimized digital subtraction angiography. Radiology, 205(1), 121-127.

- $\quad$ Kaynan, A. M., Rozenbilt, A. M., Figueroa, Kl et. al. (1999). Use of spiral computerized tomography in lieu of angiography for preoperational assessment of living renal donors Ural. 161, 1769-1775.

- $\quad$ Laugharne, M., Haslam, E., Archer, L., Jones, L., Mitchell, D., Loveday, E., \& Thornton, M. (2007). Multidetector CT angiography in live donor renal transplantation: experience from 156 consecutive cases at a single centre. Transplant International, 20(2), 156-166. dynamic image which gives the clear picture of kidney parenchyma. Rather than CTA is non-invasive and less expensive with less discomfort morbidity and radiation exposure. 3D reformatting and use formatting allow, improved vascular imaging. But in CTA is less accurate in identify prehiler branching and accessory renal artery than CA.

- Letourneau, J. G., Day, D. L., Ascher, N. L., \& CastanedaZuniga, W. R. (1988). Imaging of renaltransplants. American Journal of Roentgenology, 150(4), 833-838.

- $\quad$ Low, R. N., Martinez, A. G., Steinberg, S. M., Alzate, G. D., Kortman, K. E., Bower, B. B., ... \& Prince, S. K. (1998). Potential renal transplant donors: evaluation with gadolinium-enhanced MR angiography and MR urography.Radiology, 207(1), 165-172.

- Mandal, A. K., Cohen, C., Montgomery, R. A., Kavoussi, L. R., \& Ratner, L. E. (2001). Should the Indications for Laparascopic Live Donor Nephrectomy of the Right Kidney Be the Same As for the Open Procedure? Anomalous Left Renal Vasculature Is Not A Contraindication to Laparoscopic Left Donor Nephrectomy1. Transplantation, 71(5), 660-664.

- $\quad$ Pozniak, M. A., Balison, D. J., Lee Jr, F. T., Tambeaux, R. H., Uehling, D. T., \& Moon, T. D. (1998). CT angiography of potential renal transplant donors.Radiographics, 18(3), 565-587.

- Rankin, S. C., Jan, W., \& Koffman, C. G. (2001). Noninvasive imaging of living related kidney donors: evaluation with CT angiography and gadolinium-enhanced MR angiography. American Journal of Roentgenology, 177(2), 349-355.

- Rubin, G. D., Alfrey, E. J., Dake, M. D., Semba, C. P., Sommer, F. G., Kuo, P. C., ... \& Jeffrey, R. B. (1995). Assessment of living renal donors with spiral CT. Radiology, 195(2), 457-462.

- Rubin, G. D., Dake, M. D., Napel, S., Jeffrey Jr, R. B., McDonnell, C. H., Sommer, F. G., ... \& Williams, D. M. (1994). Spiral CT of renal artery stenosis: comparison of three-dimensional rendering techniques.Radiology, 190(1), 181-189.

- $\quad$ Smith, P. A., Ratner, L. E., Lynch, F. C., Corl, F. M., \& Fishman, E. K. (1998). Role of CT angiography in the preoperative evaluation for laparoscopic nephrectomy. Radiographics, 18(3), 589-601.

- $\quad$ Spring, D. B., Satvatierra Jr, O., Palubinskas, A. J., Amend Jr, W. J., Vincenti, F. G., \& Feduska, N. J. (1979). Results and Significance of Angiography in Potential Kidney Donors 1. Radiology, 133(1), 45-47.

- Terasaki, P. I., Cecka, J. M., Gjertson, D. W., \& Takemoto, S. (1995). High survival rates of kidney transplants from spousal and living unrelated donors. New England Journal of Medicine, 333(6) 